\title{
Adoption: a forgotten paediatric speciality
}

\author{
Mary Mather
}

\begin{abstract}
Objective-To study the medical, emotional, and developmental profile of children being considered for permanent substitute care.

Design-A retrospective analysis of 100 adoption/permanency medicals.

Setting-All children considered by the adoption and permanency panel in Greenwich, south east London, between 1994 and 1998.

Outcome measures-Analysis of medical reports completed using the British Agencies for Adoption and Fostering form $\mathrm{C}$ (under 5 years) or form $D$ (over 5 years). These include the details of a physical examination, including vision, hearing, height, and weight; emotional and behavioural concerns expressed by the foster carer and school progress.

Results-These children have complex needs. Only 31 of the 100 children were considered unlikely to have significant medical, developmental, or emotional problems.

Conclusions-Adoption medical work is becoming more specialised. Healthcare commissioners should establish minimum standards for the doctors involved in this work. As the NHS moves towards becoming a more primary care led organisation, this small service must not be forgotten. The NHS devotes few resources and little training to adoption. The medical input required to support adoption and fostering services should be recognised as a specialist paediatric service and adequately resourced.

(Arch Dis Child 1999;81:492-495)
\end{abstract}

Keywords: adoption; specialist paediatric service

Adoption is primarily a social service, but it is a social service with an important medical component. Adoption first became legal in the UK in 1926. For the next 50 years adoption practice was primarily about finding healthy babies for childless couples. The medical input to this process was minimal; essentially, healthy, newborn babies required a brief physical examination to exclude major health problems or congenital malformations. Children found to have such problems were categorised as unadoptable.

As the 20th century comes to a close, adoption is now seen as a solution to the care problems of children whose parents are unable, unwilling, or judged by the legal system as unfit to care for them. The children for whom substitute parents are now sought are likely to have complex physical, developmental, emo- tional, and educational needs. They are likely to have been damaged by inadequate parenting, abuse, and neglect. Fewer present for adoption as babies, but more as older children, who might also require placement with their siblings. Many will have had multiple previous placements, and some will have had disrupted adoptions while in the care system. ${ }^{1}$

Consequently, adoption social work practice and the medical skill and experience needed to support the substitute care of children have changed dramatically. There is little published work to show how specialised this area has become, and how medical expertise has to change to support this new population of children and their adopters. The magnitude of this change has not been realised, either by the general public or indeed by most doctors. Doctors continue to recommend adoption as a solution to infertility without appreciating that couples might not succeed in adopting the baby they desperately want, or the magnitude of the task that could face them with the adoption of an older child.

To quantify the nature of this change in medical practice, I have reviewed the adoption medicals of 100 children, performed between 1994 and 1998 in a socially deprived inner London borough with a Jarman index of 36.6 (Office of National Statistics, 1991).

\section{Method}

I analysed retrospectively 100 consecutive adoption medicals carried out by myself as consultant community paediatrician and medical advisor to the Greenwich adoption panel between 1994 and 1998. The adoption panel became a permanence panel two years into the survey. A permanence panel functions in the same way as an adoption panel, but considers those children in the care of social services who require a permanent placement; either adoption or long term fostering. The medical input was identical for both groups of children. The Greenwich adoption panel subsequently approved all the children for a permanent placement.

\section{Results}

Of the 100 children studied, 56 were boys and 44 girls; 69 were white, 11 African-Caribbean, and 20 of mixed racial heritage. There were 19 children aged $<6$ months, seven between 6 and 12 months, 20 between 1 and 2 years, 16 between 3 and 5 years, 32 between 5 and 11 years (at primary school), and six between 11 and 16 years (at secondary school).

In $85 \%$ of cases the preferred care option was adoption. No child under 5 years was approved for permanent fostering: all were approved for adoption. Twenty three of the 
Table 1 Number and ages of children in the three prognostic groups

\begin{tabular}{lrrrr}
\hline \multirow{2}{*}{ Age (years) } \\
\cline { 2 - 5 } Advice to panel $(n=100)$ & $0-1$ & $1-5$ & $5-11$ & $11-16$ \\
\hline Optimistic prognosis $(\mathrm{n}=31)$ & 18 & 10 & 1 & 2 \\
Serious problems $(\mathrm{n}=44)$ & 7 & 23 & 12 & 2 \\
Multiple problems $(\mathrm{n}=25)$ & 1 & 3 & 19 & 2 \\
\hline
\end{tabular}

32 children aged 5 to 11 years were approved for adoption. All six children over 11 were approved for permanent fostering. Thus, a decision to seek permanent fostering placement was more likely for older children or those wishing to remain in contact with their birth family. Special needs did not appear to influence which care option was recommended.

Fifty seven children were in the care of the local authority because of abuse, neglect, and poor parenting. Fifteen children were voluntarily relinquished for adoption, including three whose parents were unable to cope with their behaviour. Thirteen children were in care because of their parent's mental health problems, principally learning difficulties and schizophrenia. One or both parents of nine children were drug abusers. There were two abandoned babies whose families were never traced.

Thirty one were assessed as "normal"-that is, considered unlikely to have serious medical, developmental, or emotional problems. Ten were under 6 months, eight aged 6-12 months, six aged 1-3 years, and four aged 3-5 years. There were only three school aged children in this "normal" group, aged 7, 11, and 12 years.

Sixty children were reported to have significant emotional or behavioural difficulties. They were assessed by experienced foster carers as being difficult/unrewarding to care for or having many more problems coping with life than a normal child. For example, five had abnormal eating behaviours, four were soiling or wetting, four had inappropriate sexualised behaviour, four had severe attachment problems, and three were having nightmares even after more than one year in care. Most of the children reported with behavioural difficulties had several symptoms. The most common were high levels of aggression, anger, temper tantrums, attention seeking, mood swings, fear of change, separation anxiety, inappropriate friendliness, sibling rivalry, immaturity, and difficulty in sustaining relationships with other children.

Thirty six children had physical problems, including nine with asthma/eczema, six with short stature/failure to thrive, five with squints, four with conductive hearing loss, four with microcephaly, four with epilepsy or febrile fits, three with dyspraxia, and two with possible fetal alcohol syndrome. Important disorders first diagnosed at the medical were one child each with spastic quadriplegic cerebral palsy, pulmonary stenosis, and an undescended testis.

Four of the 62 preschool children were globally developmentally delayed. Three had been assessed and received a statement of spe- cial educational needs by the local authority as required by the Education Act 1996 . One child was attending a special school. The remaining 18 had moderate to mild delay, with delays in speech and language being most common.

Ten of the 38 school aged children between 5 and 16 years were achieving normally at school. Fourteen were receiving extra help, or in the process of being "educationally statemented", and 14 were already subjects of a full educational statement. Six of these children were attending a special school.

Many children had spent a long time in care before an adoption medical was requested, $36 \%$ for less than six months, $30 \%$ for six to 12 months, $22 \%$ for one to two years, and $12 \%$ for over two years.

An adoption medical forms the basis of the medical advice given to the adoption panel. I could offer an optimistic prognosis for a successful placement in only $31 \%$ of the children. They were those children whom I considered unlikely to have serious medical, developmental, or emotional problems. I assessed $44 \%$ of children as likely to have serious problems in placement and $25 \%$ as being difficult to place and likely to have multiple problems, particularly behavioural and attachment difficulties (table 1).

\section{Discussion}

My analysis shows that medical advisers need to be properly trained. This is far more than simply being able to carry out a physical examination. The analysis shows that growth, vision, and hearing problems are frequently found in this population. When examining such children, it is essential to have both the skills and the equipment to assess these areas accurately. It is also essential to have the knowledge and skills to identify developmental, cognitive, social, and emotional needs, major causes of adoption disruption. ${ }^{2}$

For obvious reasons there was no control group; however, local and national data do offer some comparison. The British Paediatric Association (now the Royal College of Paediatrics and Child Health) estimated in 1995 that $3 \%$ of UK children have a serious disability, and $9.6 \%$ of children under the age of 15 have a problem, either physical or behavioural, which reduces their functional capacity. ${ }^{3}$ In Greenwich, $4.5 \%$ of the childhood population are subject to a statement of special educational needs and $2.2 \%$ are placed in special schools (Health improvement plan, Bexley and Greenwich Health Authority, 1998; unpublished). In the country overall, emotional disorders are found in $10 \%$ of primary school children and $20 \%$ of adolescents. ${ }^{4}$ Children presenting for permanent substitute parenting have a significantly increased prevalence of these problems, greatest in the older children who have been more damaged by inadequate parenting, and who have been in the care system for longer.

The large number of behavioural problems, nearly three times the expected number, raises concerns. Few of the children I examined had been involved with local child and adolescent 
mental health services. The House of Commons Select Committee ${ }^{5}$ has highlighted the failure to commission sufficient child and adolescent mental health services for one of the most damaged groups of children in the community. Children attract less than $5 \%$ of the NHS mental health budget, yet represent $20 \%$ of the need. Dedicated foster carers with a large amount of experience remain the main source of therapeutic support for these children, despite little training or assistance.

In 1996, 2300 children were placed for adoption from care and 1900 adoption orders were made in England and Wales. ${ }^{6}$ Therefore, the number of adoption medicals needed in one district is small. However, the adoption service is an important resource for children. Research shows that although adopted children can have difficulties after placement, in the long term they progress well through their remaining childhood and into adult life. They fare better than children brought up by their own parents in an abusive or neglectful environment, or in institutions, and considerably better than children who have remained in the care system. ${ }^{2}$

The long term outcomes for children in permanent foster placements are less well established. A recent review compared eight studies of adoption and long term fostering. ${ }^{7}$ Although studies of this kind rarely compare like with like, six found clear advantages for adoption over long term fostering. Several were based on the comments of the children themselves. A group of American researchers ${ }^{8}$ who examined 29 studies from different countries to assess the effects of long term foster care concluded that: "adoption when available as an option should generally be pursued rather than long term foster care".

Although few in number, adopted children have complex needs. Like all other parents, potential adopters have a right to a thorough description of children's past medical problems, their current health status, and their likely future needs. It is essential to avoid distressing, expensive, and demanding placement breakdowns, which will rob a vulnerable and damaged child of yet another family. ${ }^{9}$ This is more likely to happen when adopters have insufficient information about a child or, even worse, if adopters are given an over optimistic picture of a child's needs, based solely on a single physical examination.

Although most of the information that adoptive parents need will be derived from local authority social service records, the adoption medical provides a very important overall picture of a child's physical, emotional, and developmental health and well being.

Preparing a case to present to an adoption panel is a time consuming task. I timed five cases and found an average of six hours work for each case. This use of senior medical time goes largely unrecognised because it is spread over many weeks.

The child's past medical history needs to be collated using obstetric and neonatal reports (British Agencies for Adoption and Fostering forms B1 and B2). Family history is usually obtained by the allocated social worker and information can be missed because social workers are not trained in medical history taking. The child's birth parents, who may have been alienated by the removal of their child, might only cooperate to a limited degree. Information is also gathered from hospital and community health records, which can be difficult if a child has moved repeatedly and lived in several districts. Multiple records are the norm rather than the exception.

It is estimated that nearly 750000 individuals were adopted in the UK between 1926 and the introduction of the 1989 Children Act. Most of these adults have virtually no knowledge of their own or their birth family's medical history. Modern adoption practice should end the days when a patient can only reply to a basic medical history: "I'm sorry, I don't know, I'm adopted".

I allocate one hour for an adoption examination. This is a comprehensive assessment of the child's physical, emotional, developmental, and social status. A medical report is completed using the British Agencies for Adoption and Fostering form $\mathrm{C}$ (under 5 years) or form $\mathrm{D}$ (over 5 years); the information in these forms indicates the child's future needs to the adoption panel. The same form also provides the basis of the medical information given to potential adopters. Finally, I prepare a summary for the child's new carers and general practitioner. Because of the complexity of the child's needs, the process can involve meeting potential carers and considerable liaison with health professionals in a new district of residence.

As a separate exercise, the health of the potential adopters must also be assessed and advice given to the adoption panel about their likely future health.

Ideally, medical practitioners involved in adoption work should have a knowledge of the long term consequences of child abuse and neglect. They should have an understanding of genetic illnesses that can be inherited from birth parents, and the long term consequences of parental life styles that might have involved exposure to alcohol, drugs, human immunodeficiency virus, and hepatitis B and C. Advisers also need to be able to give social workers clear advice about the effects of health problems in prospective adopters, and have an understanding of the problems that children can present to adopters. ${ }^{9}$

Multiple moves are common in the care system. In many areas, adoption medicals continue to be done as a "paper exercise", in which the medical constitutes a single physical assessment by a local doctor. This is often the general practitioner of the foster carer, who might have never seen the child, and have little knowledge of the child or family background. The social worker might not attend the medical, especially when a child is fostered out of district. The completed medical report, which through no fault of the doctor, can record little more than a physical examination, is then sent on to the agency medical adviser. This practice needs to be challenged by health authorities and by 
social services who are becoming involved in the commissioning of health services. The increasing complexity of the needs and problems of these children means that such practice needs to be reassessed.

Regulation 6.(4) of the Adoption Agencies Regulations 1983 requires the appointment of a named medical advisor to undertake this work. This is normally a consultant community paediatrician or senior clinical medical officer. It can also be carried out by a local general practitioner. There is very little peer group support within the local paediatric community for the medical advisor, and training in adoption and fostering has been confined to the voluntary sector. The British Agencies for Adoption and Fostering provide a series of excellent books, training days, and practice guidance. This training is rarely found within mainstream paediatrics. It is only recently that adoption as a topic has been added to the core syllabus for higher specialist training in paediatrics. It does not appear as a core subject in the recommended training for general practice registrars.

CONCLUSIONS

Thousands of children have benefited from the generosity and commitment of their adoptive parents. ${ }^{10}$ The ability to give a child a second chance, which is both cost effective and has been proved to be effective, is rare within paediatrics.

The resources and medical support given to the adoption and fostering services within the NHS offer such an opportunity. If adoption is to become a real option for a group of very damaged children, then appropriately trained medical advisers with experience and knowledge in paediatrics and child health must be available to support this service. The paediatricians involved must be able to function as part of a multidisciplinary team working closely with local social services, foster carers, adopters, and local paediatric services.

The paediatric contribution to adoption represents a speciality that needs to be located within mainstream paediatric services. I believe it is vital to assure the quality and continued resourcing of this small but important service within the NHS.

I would like to acknowledge the help of Dr N Islam and Dr J Wiles in completing this paper.

1 Mather M, Humphrey J, Robson J. The statutory medical and the health needs of looked after children. Time for a radical review? Adoption and Fostering 1997;21:36-40.

2 Howe D. Patterns of adoption. London: Blackwell Science, 1997.

3 British Paediatric Association Joint Working Party. The health needs of school age children. London: British Paediatric Association, 1995.

4 The NHS Advisory Service. Child and adolescent mental health services: together we stand. London: HMSO, 1995.

5 Commons Health Select Committee. Children looked after by local authorities. Commons Health Select Committee local authorities. Commons Health Sele

6 Ivaldi G. Children adopted from care. An examination of agency adoptions. London: British Agencies for Adoption and Fostering, 1998.

7 Triseliotis J. Is permanency through adoption in decline? Adoption and Fostering 1999;22:41-9.

8 McDonald TP, Allen RI, Westerfelt A, Piliavin I. Assessing the long-term effects of foster care: a research synthesis. Washington: The Child Welfare League of America, 1997.

9 Meerstadt PWD, Batty D. Model business plan for the medical aspects of adoption and planning for children looked after by aspects of adoption and planing for children looked after by Fostering, 1995.

10 Adoption. Achieving the right balance. Local authority circular ALC (198/20). London: Department of Health, 1998. 